\title{
Analisis Diskriminan Linear Robust pada Berat Bayi Lahir di RSUD Luwuk
}

\author{
NUR'ENI ${ }^{1}$, SURNI'A ${ }^{2}$, LILIES HANDAYANI ${ }^{3}$ \\ 1,2,3Program Studi Statistika, Universitas Tadulako, Indonesia \\ email: 1eniocy@yahoo.com, 2surnia.aa@gmail.com, 3lilies.stath@gmail.com
}

\begin{abstract}
ABSTRAK
Analisis diskriminan linear robust digunakan untuk mengklasifikasikan suatu pengamatan apabila dalam pengamatan tersebut terdapat pencilan. Pencilan akan menyebabkan matriks varians kovarians menjadi tidak robust. Minimum Covariance Determinant (MCD) digunakan untuk menduga sebagian pengamatan dengan meminimumkan determinan matriks kovariansi. Berat bayi lahir menurut WHO (1961) terbagi menjadi dua kategori yaitu berat bayi lahir rendah (BBL $\leq 2500$ gram) dan berat bayi lahir normal (BBL > 2500 gram). Hasil dari klasifikasi berat bayi lahir di RSUD Luwuk Kabupaten Banggai dengan menggunakan metode analisis diskriminan linear robust diperoleh tingkat akurasi sebesar $81 \%$.
\end{abstract}

Kata Kunci: Analisis Diskriminan Linear Robust, Pencilan, Berat Bayi Lahir, MCD

\begin{abstract}
Robust linear discriminant analysis is used to classify an observation if there are outliers in observation. Outliers will cause the variance covariance matrix to be not robust. Minimum Covariance Determinant (MCD) is used to predict partial observations by minimum covariance determinant matrix. The birth weight infant according to WHO (1961) is divided into two categories are low birth weight (birth weight $\leq 2500$ grams) and normal birth weight (birth weight $>2500$ grams). The results of the classification of birth weight infant in RSUD Luwuk Banggai Regency using a robust linear discriminant analysis method obtained an accuracy rate of $81 \%$.
\end{abstract}

Keywords: Robust Linear Discriminant Analysis, Outliers, Birth Weight Infant, MCD

\section{PENDAHULUAN}

Angka kematian bayi di Kabupaten Banggai sebesar 13/1000 kelahiran hidup (75 bayi), angka kematian anak balita 1/1000 kelahiran hidup (7 bayi) dan jumlah kematian neonatal di kabupaten Banggai adalah 66 bayi. Berdasarkan data tersebut penyebab kematian terbesar pada bayi adalah Berat Bayi Lahir Rendah (BBLR) dan Asfiksia (Dinkes Kabupaten Banggai, 2015).

Berat bayi lahir merupakan berat pertama janin atau bayi yang didapat setelah lahir. Untuk kelahiran hidup, berat lahir sebaiknya diukur dalam jam pertama kehidupan, sebelum terjadi penurunan berat badan yang signifikan. Menurut WHO, BBLR didefinisikan sebagai berat bayi lahir yang kurang dari 2500 gram (WHO, 1992).

Angka kejadian BBLR berdasarkan Laporan Riset Kesehatan Dasar (RISKESDAS) pada tahun 2013, Indonesia memiliki prevalensi sebesar 10,2\%. Persentase kasus BBLR tertinggi terdapat di provinsi Sulawesi Tengah sebesar 16,9\% dan persentase kasus BBLR terendah terdapat di Sumatra Utara sebesar 7,2\% (Kemenkes RI, 2015). Salah satu kabupaten yang berada di Sulawesi Tengah yaitu kabupaten Banggai memiliki jumlah kasus BBLR yang pada tiap tahunnya meningkat. Peningkatan terjadi diawali pada tahun 2011 - tahun 2014.

Pada tahun 2011, kasus BBLR sebesar 61 bayi dengan persentase 1,1\% dari 5.796 bayi yang lahir hidup. Angka tersebut kembali naik di tahun 2012 yakni sebesar 71 bayi dengan persentase 1,3\% Kemudian pada tahun 2013, jumlah kasus BBLR terus meningkat menjadi 78 bayi dengan persentase sebesar 1,3\% dari 5.939 bayi lahir hidup. Peningkatan terbesar terjadi pada tahun 2014 dengan jumlah kasus BBLR sebesar 164 bayi dari 5.733 bayi lahir hidup dengan persentase 2,8\% (Dinkes Kabupaten Banggai, 2015). 


\section{Nur'eni, dkk.}

Penelitian yang dilakukan oleh Budyanra (2016) tentang ketepatan klasifikasi fungsi diskriminan linier robust dua kelompok dengan estimator fast-MCD. Hasil pengolahan pada data simulasi diperoleh bahwa estimator fast-MCD menghasilkan rata-rata salah pengklasifikasian sebesar $11 \%$ yang lebih kecil jika dibandingkan estimator MLE dengan ratarata sebesar 22\%. Penelitian lainnya dilakukan oleh Dianiati (2013) tentang pengklasifikasian berat bayi baru lahir menggunakan analisis diskriminan linear robust dengan estimator-S. Hasil yang diperoleh yaitu kemampuan analisis diskriminan linier robust dalam klasifikasi ulang bayi baru lahir dengan ketepatan klasifikasi pada data yang mengandung pencilan adalah sebesar $80,65 \%$. Berdasarkan hasil dari beberapa penelitian tersebut, analisis diskriminan linear sangat dipengaruhi oleh pengamatan outlier sehingga penaksirnya menjadi kurang tepat pada data yang telah terkontaminasi oleh outlier. Agar analisis diskriminan linear tetap optimal dalam pengklasifikasiannya maka digunakan penaksir robust yang disebut sebagai analisis diskriminan linear robust (Budyanra, 2016).

Pada penelitian ini akan dilakukan klasifikasi berat bayi lahir di RSUD Luwuk Kabupaten Banggai dengan menggunakan satu variabel respon dengan 2 kategori yaitu BBLR dan Normal dan empat variabel prediktor. Penelitian tersebut dilakukan untuk melihat ketepatan klasifikasi dengan menggunakan analisis diskriminan linear robust dengan penduga Minimum Covariance Determinant (MCD).

\section{METODE}

\section{Lokasi Penelitian}

Penelitian ini dilakukan di RSUD Luwuk Kabupaten Banggai dengan menggunakan sampel pasien melahirkan pada bulan September-November 2018.

\section{Data}

Sampel yang digunakan dalam penelitian ini bersumber dari buku status pasien melahirkan pada Rekam Medik RSUD Luwuk Kabupaten Banggai pada bulan September-November 2018. Dalam penelitian ini terdapat enam variabel prediktor $(\mathrm{X})$ dan satu variabel respon $(\mathrm{Y})$ :

$$
\begin{array}{ll}
\mathrm{Y} & \text { : Berat Bayi Lahir dengan Kategori: } \\
& \mathrm{BBL} \leq 2500 \text { gram }=1 \text { (BBLR) } \\
& \mathrm{BBL}>2500 \text { gram }=2 \text { (Normal) } \\
\mathrm{X}_{1} & : \text { Usia Ibu (tahun) } \\
\mathrm{X}_{2} & \text { : Berat Badan Ibu pra Hamil }(\mathrm{kg}) \\
\mathrm{X}_{3} & : \text { Tinggi Badan Ibu (cm) } \\
\mathrm{X}_{4} & \text { : Usia kehamilan (minggu) }
\end{array}
$$

\section{Metode Analisis}

Prosedur analisis diskriminan linear robust dilakukan dengan software R 3.5.1. Berikut adalah langkah-langkah dalam analisis tersebut:

1. Membuat deskriptif data.

2. Pengujian perbedaan nilai vektor rata-rata dengan uji Wilk's Lambda.

3. Pengujian asumsi normal multivariat berdasarkan kelompok.

4. Pengujian kesamaan matriks varians-kovarians dengan uji Box's M.

5. Melakukan pendeteksian outlier.

6. Melakukan analisis diskriminan linear robust dan menghitung skor diskriminan linear robust untuk masing-masing pengamatan serta mengklasifikasikannya.

7. Menghitung ketepatan klasifikasi analisis diskriminan linear robust dengan metode APER dan Akurasi.

8. Interpretasi dan membuat kesimpulan. 


\section{HASIL DAN PEMBAHASAN}

\section{Deskriptif Data}

Data berat bayi lahir terdiri dari 100 pasien, dimana pasien yang memiliki bayi dengan berat lahir $\leq 2500$ gram (BBLR) berjumlah 28 pasien dan pasien dengan berat lahir $>2500$ gram (Norma) berjumlah 72 pasien. Berikut adalah diagram status berat bayi lahir:

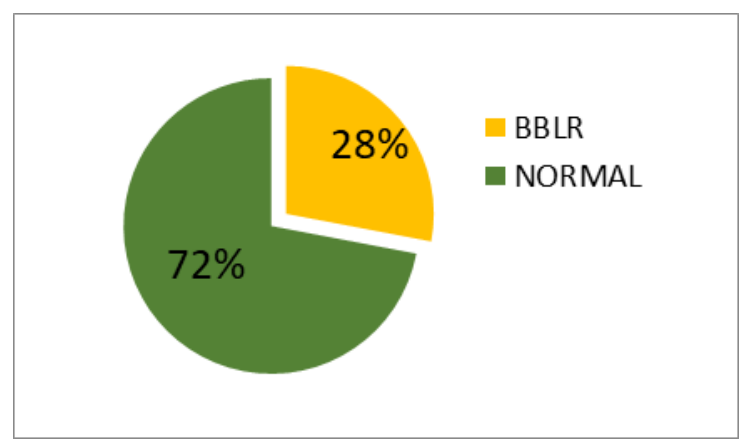

Gambar 1. Diagram Status Berat Bayi Lahir

Deskriptif data dilakukan dengan bantuan software Minitab 16, berikut adalah deskriptif data dari variabel prediktor:

Tabel 1. Deskriptif Data untuk Kelompok BBLR

\begin{tabular}{|c|c|r|r|r|}
\hline Variabel & $\mathrm{n}$ & Rata-rata & \multicolumn{1}{c|}{ Min } & \multicolumn{1}{c|}{ Maks } \\
\hline $\mathrm{X}_{1}$ & 28 & 26,93 & 16 & 42 \\
\hline $\mathrm{X}_{2}$ & 28 & 46,68 & 30 & 71 \\
\hline $\mathrm{X}_{3}$ & 28 & 152,96 & 141 & 163 \\
\hline $\mathrm{X}_{4}$ & 28 & 37,036 & 26 & 42 \\
\hline
\end{tabular}

Tabel 2. Deskriptif Data untuk Kelompok Normal

\begin{tabular}{|c|c|r|r|r|}
\hline Variabel & $\mathrm{n}$ & Rata-rata & \multicolumn{1}{c|}{ Min } & \multicolumn{1}{c|}{ Maks } \\
\hline $\mathrm{X}_{1}$ & 72 & 28,083 & 16 & 47 \\
\hline $\mathrm{X}_{2}$ & 72 & 56,39 & 35 & 73 \\
\hline $\mathrm{X}_{3}$ & 72 & 154,89 & 140 & 170 \\
\hline $\mathrm{X}_{4}$ & 72 & 39,208 & 36 & 42 \\
\hline
\end{tabular}

1. Usia Ibu

Pasien yang memiliki bayi dengan kategori BBLR rata-rata berusia 27 tahun dengan interval usia dari 16 tahun sampai 42 tahun. Sedangkan, pasien yang memiliki bayi dengan kategori Normal rata-rata berusia 28 tahun dengan interval usia dari 16 tahun sampai 47 tahun.

2. Berat Badan Ibu pra Hamil

Pasien yang memiliki bayi dengan kategori BBLR rata-rata memiliki berat badan pra hamil 47 $\mathrm{kg}$ dengan interval $30 \mathrm{~kg}$ sampai $71 \mathrm{~kg}$. Sedangkan, pasien yang memiliki bayi dengan kategori Normal memiliki rata-rata berat badan pra hamil $56 \mathrm{~kg}$, dengan interval $35 \mathrm{~kg}$ sampai $73 \mathrm{~kg}$. 


\section{Nur'eni, dkk.}

\section{Tinggi Badan Ibu}

Pasien yang memiliki bayi dengan kategori BBLR memiliki rata-rata tinggi badan $153 \mathrm{~cm}$, dengan interval $141 \mathrm{~cm}$ sampai $163 \mathrm{~cm}$. Sedangkan, pasien yang memiliki bayi dengan kategori Normal memiliki rata-rata tinggi badan $155 \mathrm{~cm}$, dengan interval $140 \mathrm{~cm}$ sampai $170 \mathrm{~cm}$.

4. Usia Kehamilan

Rata-rata lama kehamilan pasien yang memiliki bayi dengan kategori BBLR yaitu 37 minggu, dengan interval 26 minggu sampai 42 minggu. Sedangkan, pasien yang memiliki bayi dengan kategori Normal memiliki rata-rata lama kehamilan 39 minggu, dengan interval 36 minggu sampai 42 minggu.

\section{Uji Perbedaan Nilai Vektor Rata-rata}

Uji perbedaan nilai vektor rata-rata dilakukan dengan menggunakan Uji Wilks' Lambda. Berikut merupakan hipotesis dalam uji wilks' lambda:

$\mathrm{H}_{0}$ : tidak terdapat perbedaan nilai vektor rata-rata antara kelompok BBLR dan kelompok Normal.

$\mathrm{H}_{1}$ : terdapat perbedaan nilai vektor rata-rata antara kelompok BBLR dan kelompok Normal.

Kriteria pengujian wilks' lambda:

Apabila nilai $p$ value $\leq \alpha$ maka diperoleh keputusan bahwa $\mathrm{H}_{0}$ ditolak yang artinya terdapat perbedaan nilai vektor rata-rata antara kelompok BBLR dan kelompok Normal.

Tabel 3. Uji Wilks' Lambda

\begin{tabular}{|c|c|c|c|}
\hline $\begin{array}{c}\text { Wilks' } \\
\text { Lambda }\end{array}$ & $\begin{array}{c}\text { Chi- } \\
\text { square }\end{array}$ & df & p-value \\
\hline 0,69546 & 34,865 & 4 & 0,00000049 \\
\hline
\end{tabular}

Hasil dari uji wilks' lambda pada Tabel 3 diperoleh nilai $p$ value sebesar 0,00000049 dengan taraf signifikansi sebesar $5 \%$ maka $p$ value $(0,00000049) \leq \alpha(0,05)$ yang berarti Ho ditolak yang artinya terdapat perbedaan nilai vektor rata-rata antara kelompok BBLR dan kelompok Normal.

\section{Uji Asumsi Normal Multivariat}

Uji asumsi normal multivariat dilakukan dengan membuat $q-q$ plot antara jarak mahalanobis $\left(d_{i}^{2}\right)$ dan nilai chi-square kuantil pada masing-masing kelompok. berikut hipotesis yang digunakan dalam uji asumsi normal multivariat:

$\mathrm{H}_{0}$ : semua variabel independen mengikuti sebaran normal multivariat

$\mathrm{H}_{1}$ : semua variabel independen tidak mengikuti sebaran normal multivariat

Kriteria pengujian:

Jika plot membentuk garis lurus dan lebih dari $50 \%$ nilai $d_{i}^{2} \leq x_{1-\varkappa_{j} p}^{2}$ maka sejumlah $p$ variabel mengikuti sebaran normal multivariat (Johnson dan Wichern, 2007). 


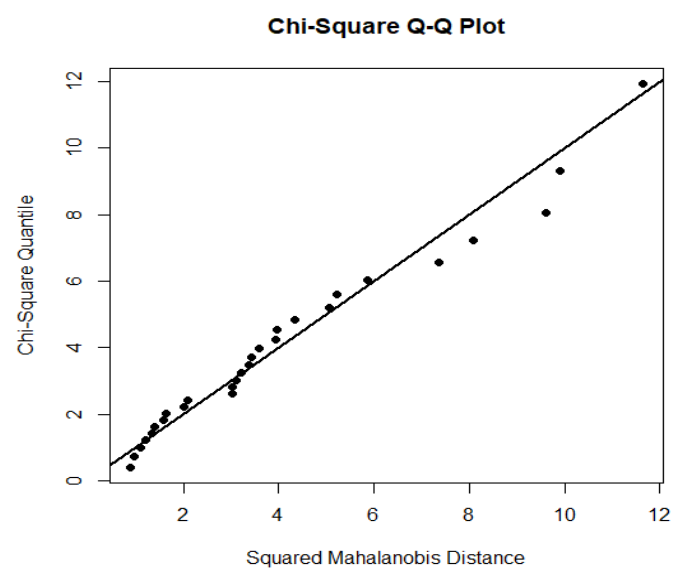

Gambar 2. QQ-Plot untuk Kelompok Data BBLR

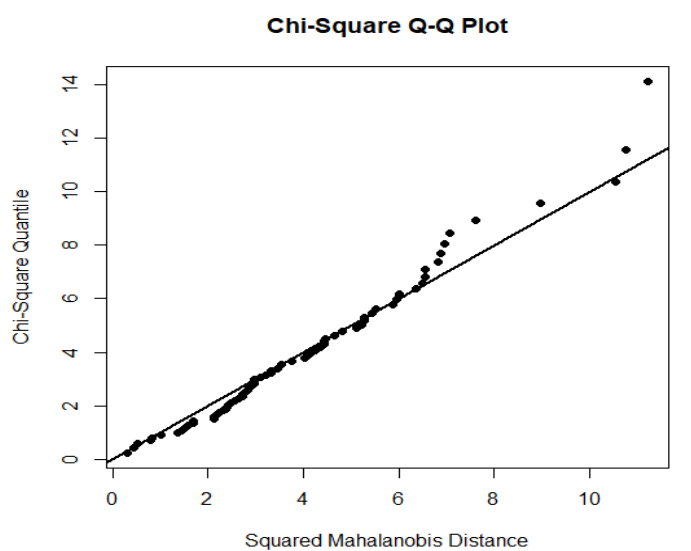

Gambar 3. QQ-Plot untuk Kelompok Data Normal

Hasil dari q-q plot antara kelompok BBLR dan kelompok Normal pada Gambar 2 dan Gambar 3 menunjukkan bahwa sekumpulan data membentuk suatu garis lurus dan lebih dari $50 \%$ nilai jarak mahalanobis $\left(d_{i}^{2}\right)$ kurang dari nilai chi-square $\left(x_{0,95 ; 4}^{2}=9,487729\right)$ maka dapat dikatakan bahwa semua variabel pada kelompok data BBLR dan kelompok data Normal mengikuti sebaran normal multivariat.

\section{Uji Kehomogenan Matriks Varians Kovarian}

Uji kehomogenan matriks varians kovarian menggunakan uji Box's M dengan hipotesis sebagai berikut:

$\mathrm{H}_{0}$ : tidak terdapat perbedaan matriks varians kovarian antara kelompok BBLR dan kelompok Normal.

$\mathrm{H}_{1}$ : terdapat perbedaan matriks varians kovarian antara kelompok BBLR dan kelompok Normal.

Kriteria pengujian Box's M:

Apabila nilai $p$ value $\leq \alpha$ maka diperoleh keputusan bahwa Ho ditolak yang artinya terdapat perbedaan matriks varians kovarian antara kelompok BBLR dan kelompok Normal. 
24 Nur'eni, dkk.

Tabel 4. Uji Box's M

\begin{tabular}{|l|l|l|}
\hline Chi-square & $d f$ & $p$-value \\
\hline 51,707 & 10 & 0,00000013 \\
\hline
\end{tabular}

Hasil dari pengujian Box's M pada Tabel 4 diperoleh nilai $\mathrm{p}$ value sebesar 0,00000013 dengan taraf signifikansi sebesar $5 \%$ maka $\mathrm{p}$ value $(0,00000013) \leq \alpha(0,05)$ yang berarti HO ditolak yang artinya terdapat perbedaan matriks varians kovarian antara kelompok BBLR dan kelompok Normal.

\section{Pendeteksian Pencilan}

Pencilan merupakan suatu pengamatan yang terletak jauh dari kumpulan data lainnya. Jarak robust merupakan ukuran jarak yang digunakan untuk mendeteksi pencilan dengan kemampuan lebih baik daripada jarak mahalanobis (Rousseuw dan Driesen, 1999).

Kriteria pengujian:

Apabila observasi $x_{\tilde{i}}$ mempunyai nilai kuadrat jarak robust yang lebih besar dari nilai chisquare dengan derajat bebas $p\left(d_{M D}^{2}>x_{1-\kappa, p}^{2}\right)$ maka observasi $x_{i}$ termasuk outlier (Putra, 2013).

Berdasarkan hasil dari deteksi pencilan data berat bayi lahir diperoleh bahwa pada kelompok BBLR terdapat lima data pencilan yaitu pada data ke- 2,6,9,17,23 dari total keseluruhan 28 data. Sedangkan, pada kelompok data Normal terdapat delapan data pencilan yaitu pada data ke-1,5,7,18,29,32,33,53 dari total keseluruhan 72 data.

\section{Analisis Diskriminan Linear Robust}

Analisis diskriminan linear robust digunakan apabila terdapat data yang mengandung pencilan (outlier). Dalam pembentukan fungsi skor diskriminan linear, apabila terdapat observasi outlier maka akan berpengaruh sangat besar pada pembentukan fungsi tersebut. Hal itu dikarenakan matriks sampel rata-rata dan sampel kovarians sangat sensitif terhadap adanya observasi outlier. Untuk mengatasi masalah tersebut maka digunakan penduga Minimum Covariance Deterinant (MCD) untuk mengestimasi matriks kovarian (Rousseeuw dan Driessen, 1999).

Berdasarkan hasil dari deteksi pencilan diperoleh bahwa pada data berat bayi lahir terdapat beberapa pengamatan yang merupakan data pencilan. Sehingga, digunakan analisis diskriminan linear robust.

\section{Fungsi Skor Diskriminan Linear Robust}

Suatu pengamatan dapat diklasifikasikan dalam kelompok BBLR atau kelompok Normal dilakukan dengan cara menghitung skor diskriminan linear robust. Fungsi diskriminan linear robust dengan menggunakan penduga minimum covariance determinant (MCD) adalah sebagai berikut:

$\hat{d}_{k}(x)=\overline{\mathbf{x}}_{M C D k}^{T} \mathbf{S}_{M C D}^{-1} x-\frac{1}{2} \overline{\mathbf{x}}_{M C D k}^{T} \mathbf{S}_{M C D}^{-1} \overline{\mathbf{x}}_{M C D}+\ln p_{k}$

Menurut Johnson dan Wichern (2007), fungsi tersebut digunakan untuk mengklasifikasikan suatu observasi ke dalam kelompok ke $k$ jika skor diskriminan linear sebagai berikut:

$$
\hat{d}_{k}(x)=\max \left\{\hat{d}_{1}(x), \hat{d}_{2}(x), \ldots, \hat{d}_{g}(x)\right\}
$$

Berdasarkan output analisis diskriminan linear robust dengan menggunakan software $\mathrm{R}$ 3.5.1 diperoleh nilai peluang kedua kelompok, vektor rata-rata kedua kelompok dan matriks varianskovarians gabungan sebagai berikut: 
Tabe1 5. Peluang dari masing-masing Kelompok

\begin{tabular}{|c|c|c|}
\hline Kelompok & $N$ & Nilai Peluang \\
\hline BBLR & 28 & 0,28 \\
\hline Normal & 72 & 0,72 \\
\hline
\end{tabular}

Vektor rata-rata untuk masing-masing kelompok:

$$
\bar{x}_{M C D_{1}}=\left[\begin{array}{c}
27,439 \\
47,690 \\
152,783 \\
38,693
\end{array}\right] \quad \bar{x}_{M C D_{2}}=\left[\begin{array}{c}
27,475 \\
53,875 \\
154,920 \\
39,271
\end{array}\right]
$$

Matriks varians-kovarians gabungan:

$$
S_{\text {gabMCD }}=\left[\begin{array}{cccc}
73,004 & 25,460 & -0,323 & -0,502 \\
25,460 & 83,582 & 26,609 & 0,815 \\
-0,323 & 26,609 & 42,844 & -2,954 \\
-0,502 & 0,815 & -2,954 & 2,334
\end{array}\right]
$$

Nilai vektor rata-rata kedua kelompok dan matriks varians-kovarians gabungan tersebut digunakan untuk membentuk fungsi diskriminan linear dengan menggunakan salah satu objek penelitian. Berikut adalah perhitungan dalam menentukan kelompok dari suatu objek dengan data sebagai berikut:

Diketahui bahwa nilai peluang untuk pasien yang memiliki BBLR yaitu 0,28 dan nilai peluang untuk pasien yang memiliki berat bayi Normal yaitu 0,72. Apabila seorang pasien berusia 23 tahun, memiliki berat badan pra hamil $53 \mathrm{~kg}$, tinggi badan $162 \mathrm{~cm}$, dan lama kehamilan 39 minggu maka:

1. Fungsi Skor Diskriminan Linear Robust untuk Kelompok BBLR

$$
\begin{aligned}
\bar{d}_{1}(x)= & \bar{x}_{M C D_{1}}^{-T} S_{\text {gabMCD }}^{-1} x-\frac{1}{2} \bar{x}_{M C D_{1}} S_{\text {gabMCD }}^{-1} \bar{x}_{M C D_{1}}+\ln p_{1} \\
= & {\left[\begin{array}{llll}
27,439 & 47,690 & 152,783 & 38,693
\end{array}\right]\left[\begin{array}{cccc}
73,004 & 25,460 & -0,323 & -0,502 \\
25,460 & 83,582 & 26,609 & 0,815 \\
-0,323 & 26,609 & 42,844 & -2,954 \\
-0,502 & 0,815 & -2,954 & 2,334
\end{array}\right]\left[\begin{array}{c}
23 \\
53 \\
162 \\
39
\end{array}\right]-} \\
& \frac{1}{2}\left[\begin{array}{llllll}
27,439 & 47,690 & 152,783 & 38,693
\end{array}\right]\left[\begin{array}{cccc}
73,004 & 25,460 & -0,323 & -0,502 \\
25,460 & 83,582 & 26,609 & 0,815 \\
-0,323 & 26,609 & 42,844 & -2,954 \\
-0,502 & 0,815 & -2,954 & 2,334
\end{array}\right] \\
& {\left[\begin{array}{c}
27,439 \\
47,690 \\
152,783 \\
38,693
\end{array}\right]+\ln (0,28) }
\end{aligned}
$$


26 Nur'eni, dkk.

$$
\begin{aligned}
& \bar{d}_{1}(x)=2037,0238+\frac{1}{2}(1984,477)-1,2729 \\
& \bar{d}_{1}(x)=2037,0238-992,2389-1,2729 \\
& \bar{d}_{1}(x)=1043,5119
\end{aligned}
$$

2. Fungsi Skor Diskriminan Linear Robust untuk Kelompok BBL Normal

$$
\begin{aligned}
\bar{d}_{2}(x)= & \bar{x}_{M C D_{2}} S_{\text {gabMCD }}^{-1} x-\frac{1}{2} \bar{x}_{M C D_{2}} S_{\text {gabMCD }}^{-1} \bar{x}_{M C D_{2}}+\ln p_{2} \\
= & {\left[\begin{array}{llll}
27,475 & 53,875 & 154,920 & 39,271
\end{array}\right]\left[\begin{array}{cccc}
73,004 & 25,460 & -0,323 & -0,502 \\
25,460 & 83,582 & 26,609 & 0,815 \\
-0,323 & 26,609 & 42,844 & -2,954 \\
-0,502 & 0,815 & -2,954 & 2,334
\end{array}\right]\left[\begin{array}{c}
23 \\
53 \\
162 \\
39
\end{array}\right]-} \\
& \frac{1}{2}\left[\begin{array}{lllll}
27,475 & 53,875 & 154,920 & 39,271
\end{array}\right]\left[\begin{array}{cccc}
73,004 & 25,460 & -0,323 & -0,502 \\
25,460 & 83,582 & 26,609 & 0,815 \\
-0,323 & 26,609 & 42,844 & -2,954 \\
-0,502 & 0,815 & -2,954 & 2,334
\end{array}\right] \\
\bar{d}_{2}(x)= & {\left[\begin{array}{c}
2053,5082+\frac{1}{2}(2016,5554)-0,3285 \\
53,875 \\
154,920 \\
39,271
\end{array}\right]+\ln (0,72) } \\
\bar{d}_{2}(x)= & 2053,5082-1008,278-0,3285 \\
\bar{d}_{2}(x)= & 1044,9020
\end{aligned}
$$$$
\frac{1}{2}\left[\begin{array}{llll}
27,475 & 53,875 & 154,920 & 39,271
\end{array}\right]\left[\begin{array}{cccc}
73,004 & 25,460 & -0,323 & -0,502 \\
25,460 & 83,582 & 26,609 & 0,815 \\
-0,323 & 26,609 & 42,844 & -2,954 \\
-0,502 & 0,815 & -2,954 & 2,334
\end{array}\right]
$$

Setelah diperoleh fungsi skor diskriminan linear untuk masing-masing kelompok, selanjutnya menentukan klasifikasi dari suatu objek yang masuk ke dalam kelompok 1 atau kelompok 2 dengan kriteria $\hat{d}_{k}(x)=\max \left\{\hat{d}_{1}(x), \hat{d}_{2}(x)\right\}$.

Sehingga,

$$
\begin{aligned}
\hat{d}_{k}(x) & =\max \left\{\hat{d}_{1}(x), \hat{d}_{2}(x)\right\} \\
& =\max \{(1043,5119),(1044,9020)\} \\
& =1044,9020 \\
& =\hat{d}_{2}(x)
\end{aligned}
$$

Berdasarkan nilai $\hat{d}_{1}(x)$ dan $\hat{d}_{2}(x)$, nilai maksimum yang diperoleh adalah $\hat{d}_{2}(x)$ sehingga seorang pasien dengan data di atas masuk ke dalam kelompok 2 atau kelompok yang memiliki berat bayi lahir normal. Hasil pengelompokkan data lainnya tercantum dalam tabel klasifikasi. 


\section{Ketepatan Klasifikasi Fungsi Diskriminan Linear Robust}

Berikut dalah hasil klasifikasi dari fungsi diskriminan linear robust:

Tabel 6. Hasil Klasifikasi Fungsi Diskriminan Linear Robust

\begin{tabular}{|c|c|c|c|}
\hline \multirow{2}{*}{ Aktual } & \multicolumn{2}{|c|}{ Prediksi } & \multirow{2}{*}{ Total } \\
\cline { 2 - 3 } & 1 & 2 & \\
\hline 1 & 10 & 18 & 28 \\
\hline 2 & 1 & 71 & 72 \\
\hline
\end{tabular}

Ketepatan klasifikasi diperoleh dari nilai akurasi. Berdasarkan pada Tabel 5, nilai akurasi diperoleh dengan menggunakan rumus berikut:

$$
\begin{aligned}
\text { Akurasi } & =\frac{n_{11}+n_{22}}{n_{1}+n_{2}} \times 100 \% \\
& =\frac{10+71}{28+72} \times 100 \% \\
& =\frac{81}{100} \times 100 \% \\
& =81 \%
\end{aligned}
$$

Berdasarkan perhitungan tersebut, diperoleh nilai akurasi sebesar $81 \%$.

\section{KESIMPULAN}

Klasifikasi berat bayi lahir dengan menggunakan analisis diskriminan linear robust menghasilkan nilai akurasi sebesar 81\%. Sehingga, dapat disimpulkan bahwa pada data yang mengandung pencilan analisis diskriminan linear robust dapat menghasilkan ketepatan klasifikasi yang baik.

\section{DAFTAR PUSTAKA}

Budyanra. (2016). Ketepatan Pengklasifikasian Fungsi Diskriminan Linier Robust Dua Kelompok dengan Metode Fast Minimum Covariate Determinant (Fast-MCD). Jurnal Statistika, Vol. 4, No. 2. Jakarta: Sekolah Tinggi Ilmu Statistik.

Dianiati, A. (2013). Analisis Diskriminan Linier Robust pada Pengklasifikasian Berat Bayi Baru Lahir di Puskesmas Manyar Kabupaten Gresik Tahun 2012. Malang: Universitas Brawijaya.

Dinkes Kabupaten Banggai. (2015). Profil Kesehatan Kabupaten Banggai Tahun 2014. Kabupaten Banggai.

Johnson, R. A., \& Wichern, D. W. (2007). Applied Multivariate Statistical Analysis. United States of America: Prentice Hall Inc.

Kemenkes RI. (2015). Profil Kesehatan Indonesia 2014. Jakarta: Kementrian Kesehatan RI.

Putra, T. H., (2013), Perbandingan Penduga Minimum Covariance Determinant (MCD) dengan Maximum Likelihood Estimation (MLE) pada Analisis Diskriminan untuk Data yang Mengandung Pencilan, Skripsi Departemen Statistika, Bogor: Institut Pertanian Bogor.

Rousseeuw, P., \& Driessen, K. V. (1999). A Fast Algorithm For The Minimum Covariance Determinant Estimator. Technometrics 41 (3), 212-223.

WHO. (1992). International Statistical Classification of Diseases and Related Health Problems. Tenth Revisio. Geneva: World Health Organization 